Article

\title{
Synthesis and Biological Evaluation of Amino Chalcone Derivatives as Antiproliferative Agents
}

\author{
Chao-Fan Lu ${ }^{1, \dagger}{ }^{\dagger}$, Sheng-Hui Wang ${ }^{1,+}$, Xiao-Jing Pang ${ }^{1,2,+}{ }^{+}$Ting Zhu ${ }^{2}$, Hong-Li Li ${ }^{1}$, \\ Qing-Rong Li ${ }^{1}$, Qian-Yu Li ${ }^{1}$, Yu-Fan Gu ${ }^{1}$, Zhao-Yang Mu ${ }^{1}$, Min-Jie Jin ${ }^{1}$, Yin-Ru Li ${ }^{1}$, \\ Yang-Yang $\mathrm{Hu}^{3}$, Yan-Bing Zhang ${ }^{2}$, Jian Song ${ }^{1,2, *}$ and Sai-Yang Zhang ${ }^{1,2,4, *(D)}$ \\ 1 School of Basic Medical Sciences, Zhengzhou University, Zhengzhou 450001, China; \\ chaofanlu@stu.zzu.edu.cn (C.-F.L.); thekingwinglory@outlook.com (S.-H.W.); summer_pxj@163.com (X.-J.P.); \\ Hollyly1@outlook.com (H.-L.L.); $15318989671 @ 163 . c o m$ (Q.-R.L.); lqy1021@stu.zzu.edu.cn (Q.-Y.L.); \\ 18838078036@163.com (Y.-F.G.); QQ2743757146@163.com (Z.-Y.M.); Agile321@163.com (M.-J.J.); \\ 202012402016083@gs.zzu.edu.cn (Y.-R.L.) \\ 2 School of Pharmaceutical Sciences, Institute of Drug Discovery \& Development, Key Laboratory of \\ Advanced Drug Preparation Technologies (Ministry of Education), Zhengzhou University, \\ Zhengzhou 450001, China; 17671140381@sina.cn (T.Z.); zhangyb@zzu.edu.cn (Y.-B.Z.) \\ 3 Faculty of Science, The University of Melbourne, Melbourne VIC 3010, Australia; \\ YANGYANGH1@student.unimelb.edu.au \\ 4 Henan Institute of Advanced Technology, Zhengzhou University, Zhengzhou 450001, China \\ * Correspondence: mumuandzz@163.com (J.S.); saiyangz@zzu.edu.cn (S.-Y.Z.) \\ + These authors contributed equally to this work.
}

Academic Editors: Jiang Wang, Liang-Ren Zhang, Peng Zhan, Qi-Dong You, Tian-Miao Ou and Xiao-Yun Lu

Received: 29 September 2020; Accepted: 24 November 2020; Published: 25 November 2020

\begin{abstract}
Chalcone is a common scaffold found in many biologically active compounds. The chalcone scaffold was also frequently utilized to design novel anticancer agents with potent biological efficacy. Aiming to continue the research of effective chalcone derivatives to treat cancers with potent anticancer activity, fourteen amino chalcone derivatives were designed and synthesized. The antiproliferative activity of amino chalcone derivatives was studied in vitro and 5-Fu as a control group. Some of the compounds showed moderate to good activity against three human cancer cells (MGC-803, HCT-116 and MCF-7 cells) and compound 13e displayed the best antiproliferative activity against MGC-803 cells, HCT-116 cells and MCF-7 cells with $\mathrm{IC}_{50}$ values of $1.52 \mu \mathrm{M}$ (MGC-803), $1.83 \mu \mathrm{M}$ (HCT-116) and $2.54 \mu \mathrm{M}$ (MCF-7), respectively which was more potent than the positive control (5-Fu). Further mechanism studies were explored. The results of cell colony formatting assay suggested compound 10e inhibited the colony formation of MGC-803 cells. DAPI fluorescent staining and flow cytometry assay showed compound 13e induced MGC-803 cells apoptosis. Western blotting experiment indicated compound 13e induced cell apoptosis via the extrinsic/intrinsic apoptosis pathway in MGC-803 cells. Therefore, compound 13e might be a valuable lead compound as antiproliferative agents and amino chalcone derivatives worth further effort to improve amino chalcone derivatives' potency.
\end{abstract}

Keywords: chalcone; synthesis; antiproliferative; cell apoptosis

\section{Introduction}

Chalcone is a common scaffold found in many biologically active compounds [1]. Natural chalcone products and synthetic chalcone derivatives have shown many interesting pharmacological activities including anti-bacterial [2-4], anti-malarial [5-7], anti-fungal [8-10], anti-HIV [11-13], 
anti-inflammatory [14-16] and anti-cancer [17-26] activities. Especially, chalcone compounds as a class of anticancer agents have exhibited promising therapeutic efficacy and clinical potentials for the treatment of human tumors. In fact, many groups have reported various chalcone derivatives with potent anticancer activity. (E)-3-(3-hydroxy-4-methoxyphenyl)-1-(3,4,5-trimethoxyphenyl)prop-2-en-1-one 1 [22] displayed remarkable antiproliferative activities against and was identified as a tubulin inhibitor. (E)-3-(4-methoxyphenyl)-1-(3,4,5-trimethoxyphenyl)prop-2-en-1-one 2 exhibited the antiproliferative activity against $\mathrm{K} 562$ cell line with an $\mathrm{IC}_{50}$ of $4.5 \mu \mathrm{M}$ [23]. Compound 3 [24] named millepachine showed inhibitory effect in several human cancer cells, especially in HepG2 cells with an $\mathrm{IC}_{50}$ of $1.51 \mu \mathrm{M}$, and induced G2/M arrest by inhibiting CDK1 activity and causing apoptosis via ROS-mitochondrial apoptotic pathway. Moreover, the chalcone scaffold was also frequently utilized to design novel anticancer agents with potent biological efficacy. Pyridyl-indole based heteroaryl chalcone 4 [25] containing a sulfonamide group exhibited significant inhibition of hCA IX activity $\left(\mathrm{IC}_{50}=0.13 \mu \mathrm{M}\right)$ and MCF-7 cells $\left(\mathrm{IC}_{50}=12.2 \mu \mathrm{M}\right)$. Sorafenib analogues bearing chalcone unit 5 [26] showed well anticancer activity against MCF-7 cells $\left(\mathrm{IC}_{50}=3.88 \mu \mathrm{M}\right)$ and PC-3 cells $\left(\mathrm{IC}_{50}=3.15 \mu \mathrm{M}\right)$ and potent activity on VEGFR-2/KDR kinase $\left(\mathrm{IC}_{50}=0.72 \mu \mathrm{M}\right)$. Therefore, chalcone might be a valuable lead scaffold to design novel anticancer agents and there is an urgent need to discover more effective compounds to treat cancers. In this work, we continued with our efforts on chalcone derivatives to discover potent anticancer agents for the treatment of human cancers (Figure 1).

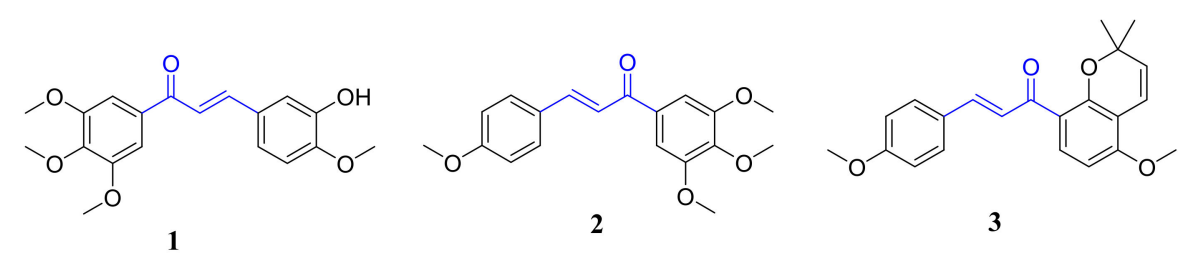

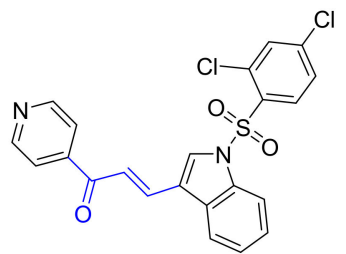

4

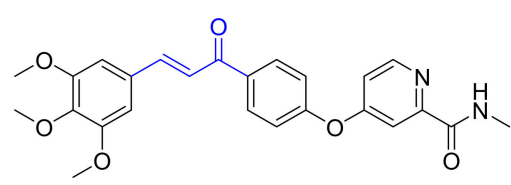

5

Figure 1. Structures of chalcone derivates as antitumor agents previously reported.

The combinations of chalcone scaffold with other anticancer fragment by the molecular hybridization strategy are a common and effective methods to design novel anticancer chalcone derivatives. Recently, our group also has reported several series of novel chalcone derivatives by the molecular hybridization strategy that exhibited potent antiproliferative activity against human cancer cells [27-30]. Chalcone-dithiocarbamate 6 exhibited the inhibitory activity against MGC-803 cells $\left(\mathrm{IC}_{50}=1.74 \mu \mathrm{M}\right)$. Chalcone-1,2,3-triazole-azole 7 displayed the good inhibitory activity against MGC-803 cells $\left(\mathrm{IC}_{50}=4.26 \mu \mathrm{M}\right)$. The modification of amino groups usually leads to better antitumor activity [31,32]. For example, novel 4-substituted coumarin derivative 9 were optimized and synthesized form 4-((3-amino-4-methoxyphenyl) (methyl)amino)-2H-chromen-2-one 8 [32]. Compound 9 exhibited more potent antiproliferative activity against SKVO3 cells $\left(\mathrm{IC}_{50}=3.5 \mathrm{nM}\right)$ then compound $8\left(\mathrm{IC}_{50}=23.4 \mathrm{nM}\right)$. In this work, as the continuation of our studies on novel chalcone derivatives as cancer agents, the modification and optimization of amino group of (E)-1-(4-aminophenyl)-3-(3,4,5-trimethoxyphenyl) prop-2-en-1-one 10 was explored. Eleven amino chalcone derivatives were designed, synthesized and tested its antiproliferative activity against MGC-803 cells, HCT-116 cells and MCF-7 cells (Figure 2). 

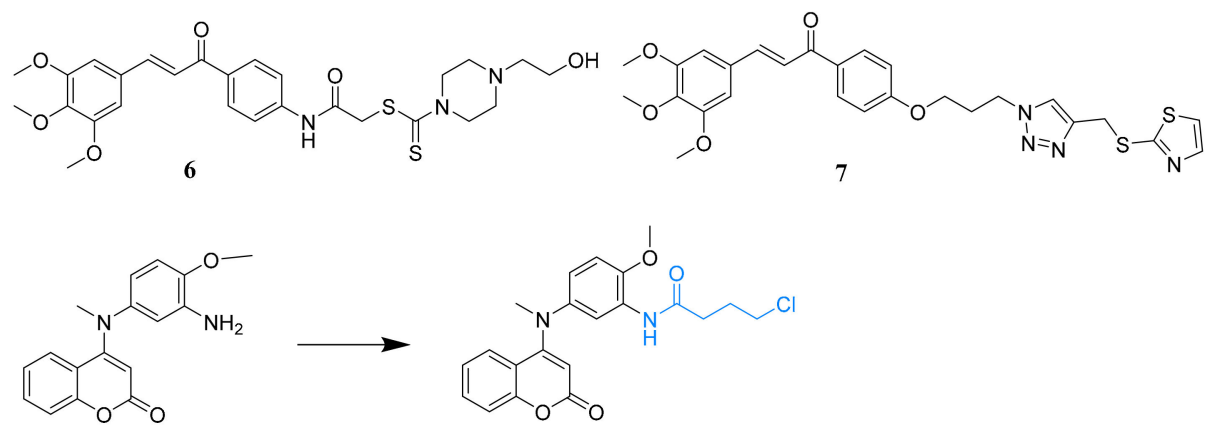

$$
8
$$

9

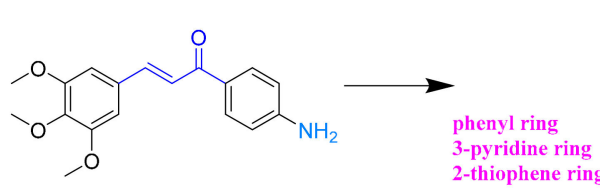

10

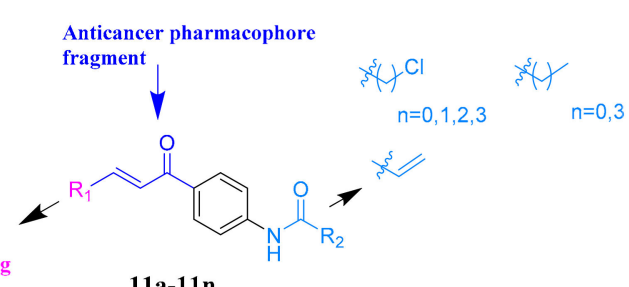

11a-11n

Figure 2. Reported and proposed anticancer chalcone and coumarin derivatives.

\section{Results and Discussion}

\subsection{Chemistry}

Target amino chalcone derivatives were synthesized by outlined procedures in Scheme 1. Commercially available aldehydes $\mathbf{1 1 a}-\mathbf{h}$ reacted with 4 -aminoacetophenone to afford compounds 12a-h. Compounds 12a-h then reacted with substituted acyl chloride intermediates in DCM to give compounds 13a-n. Characterization of compounds 13a-n was carried out by means of NMR and HREI-mass spectra which were showed in the Supplementary Materials.

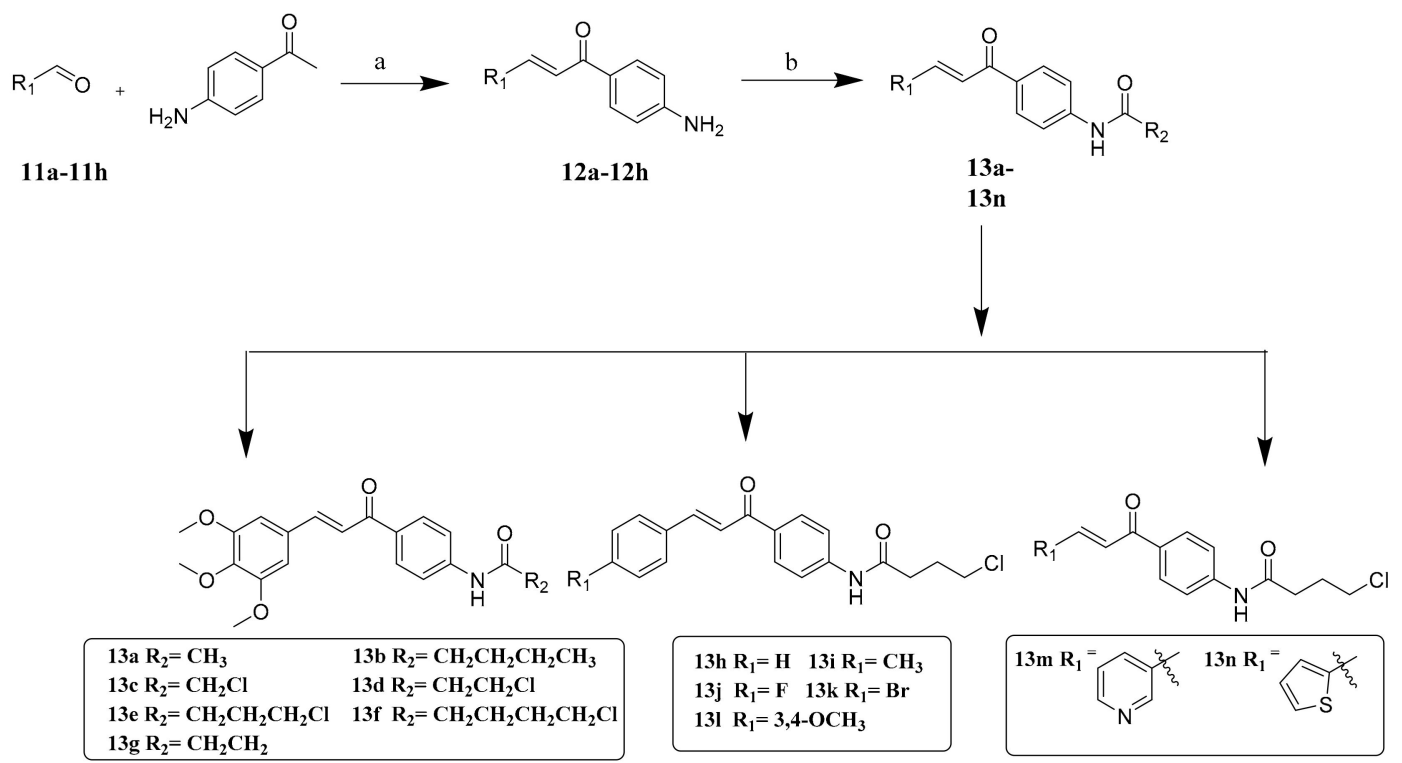

Reagents and conditions: a) EtOH, $\mathrm{NaOH}, 80^{\circ} \mathrm{C}, 8 \mathrm{~h}$; b) acyl chloride derivatives, TEA, DCM, rt, 5 h.

Scheme 1. Synthesis of compounds 13a-n. 


\subsection{Antiproliferative Activity and Structure Activity Relationship Analysis}

The in vitro antiproliferative activities of new target compounds 13a-n were evaluated against four human cancer cell lines (MGC-803, HCT-116 and MCF-7) using MTT assay and 5-Fu as a positive drug. The following Table 1 depicted the results of in vitro antiproliferative activity.

Table 1. In vitro antiproliferative activities of compounds 10a-p against human cancer cells.

\begin{tabular}{cccc}
\hline \multirow{2}{*}{ Compounds } & \multicolumn{3}{c}{ IC $_{\mathbf{5 0}}(\mu \mathrm{mol} / \mathrm{L})^{\mathbf{a}}$} \\
\cline { 2 - 4 } & MGC-803 & HCT-116 & MCF-7 \\
\hline $13 \mathrm{a}$ & $3.81 \pm 0.22$ & $4.012 \pm 0.31$ & $3.56 \pm 0.17$ \\
$13 \mathrm{~b}$ & $4.08 \pm 0.24$ & $6.72 \pm 0.28$ & $3.11 \pm 0.34$ \\
$13 \mathrm{c}$ & $1.88 \pm 0.22$ & $2.83 \pm 0.03$ & $3.12 \pm 0.01$ \\
$13 \mathrm{~d}$ & $1.64 \pm 0.18$ & $2.40 \pm 0.26$ & $2.12 \pm 0.13$ \\
$13 \mathrm{e}$ & $1.52 \pm 0.12$ & $1.83 \pm 0.20$ & $2.54 \pm 0.18$ \\
$13 \mathrm{f}$ & $3.01 \pm 0.11$ & $4.28 \pm 0.32$ & $4.45 \pm 0.11$ \\
$13 \mathrm{~g}$ & $1.83 \pm 0.20$ & $1.12 \pm 0.11$ & $2.06 \pm 0.21$ \\
$13 \mathrm{~h}$ & $22.1 \pm 0.75$ & $13.1 \pm 0.51$ & $22.2 \pm 0.83$ \\
$13 \mathrm{i}$ & $16.8 \pm 0.82$ & $13.1 \pm 0.61$ & $17.6 \pm 0.51$ \\
$13 \mathrm{j}$ & $>40$ & $>40$ & $>40$ \\
$13 \mathrm{k}$ & $>40$ & $>40$ & $>40$ \\
$13 \mathrm{l}$ & $16.3 \pm 0.65$ & $>40$ & $10.1 \pm 0.73$ \\
$13 \mathrm{~m}$ & $5.41 \pm 0.30$ & $6.12 \pm 0.41$ & $6.62 \pm 0.48$ \\
$13 \mathrm{n}$ & $>40$ & $12.5 \pm 0.28$ & $21.2 \pm 1.12$ \\
$5-\mathrm{Fu}$ & $6.82 \pm 1.12$ & $14.4 \pm 1.73$ & $12.1 \pm 1.28$ \\
\hline
\end{tabular}

${ }^{\mathrm{a}}$ In vitro antiproliferative activity was assayed by exposure for $48 \mathrm{~h}$.

Compounds 13a-g were synthesized and evaluated against MGC-803, HCT-116 and MCF-7 cells. In this series of compounds, we first explored the importance of the substituent groups of $R_{2}$ on the antiproliferative activities of compounds with a 3,4,5-trimethoxyphenyl group of $R_{1}$. As shown in Table 1, most of the compounds 13a-g exhibited potent inhibitory efficacy against MGC-803, HCT-116 and MCF-7 cells with $\mathrm{IC}_{50}$ values less than $10 \mu \mathrm{M}$ than the positive drug 5-Fu. The inhibitory efficacy of compounds $\mathbf{1 3} \mathbf{a}-\mathbf{g}$ varies with its substituent groups of $R_{2}$. Compound 13e with a chloropropyl group of $\mathrm{R}_{2}$ displayed most the potent in vitro antiproliferative activity with $\mathrm{IC}_{50}$ values of $1.52 \mu \mathrm{M}$ (MGC-803), $1.83 \mu \mathrm{M}$ (HCT-116) and $2.54 \mu \mathrm{M}$ (MCF-7), respectively. Compared compound 13c, 13d, 13f and 13e, proper carbon liner length of $R_{2}$ group enhanced anticancer activity. Compound $13 \mathrm{~g}$ with a vinyl group of $R_{2}$ also showed potent antiproliferative activity against three human cancer cells. With compound $13 \mathrm{e}$ in hand, we started to focus our attention on the $\mathrm{R}_{1}$ moiety of compounds with a chloropropyl group of $\mathrm{R}_{2}$. Most of the target compounds exhibited weaker antiproliferative activity compared to compounds with a 3,4,5-trimethoxyphenyl group of $R_{1}$ and the positive drug 5-Fu. Compared compounds 13h, 13i, 13j, 131 and 13e, Compounds with electron-donating groups on phenyl group of $\mathrm{R}_{1}$ showed improved inhibitory efficacy then compounds with an unsubstituted group and electron-withdrawing groups. What's more, compounds $\mathbf{1 3} \mathbf{m}-\mathbf{n}$, with heterocyclic groups of $\mathrm{R}_{1}$ didn't showed improved inhibitory activity against three human cancer cells.

Notably, compounds 13e exhibited highest activity against three test human cancer cells. Therefore, compounds 13e also were evaluated against non-cancer cell lines GES-1 cells. As shown in Table 2, Compounds $13 \mathbf{e}$ exhibited weaker activity against GES-1 cells with an $\mathrm{IC}_{50}$ value of $8.22 \mu \mathrm{M}$ than compounds 13e. The selectivity of compounds 13e between MGC-803 cells and GES-1 cells 5.4-fold selectivity.

$$
\mathrm{A}=\mathrm{IC}_{50}(\mathrm{GES}-1) / \mathrm{IC}_{50}(\mathrm{MGC}-803)
$$


Table 2. In vitro anti-proliferative activity of 13e against gastric cancer cells (MGC-803) and non-cancer cell lines (GES-1).

\begin{tabular}{cccc}
\hline \multirow{2}{*}{ Compd. } & \multicolumn{2}{c}{$\mathrm{IC}_{\mathbf{5 0}}(\boldsymbol{\mu M})^{\text {a }}$} & Fold Selectivity \\
\cline { 2 - 4 } & MGC-803 & GES-1 & A \\
\hline $13 \mathrm{~g}$ & 1.52 & 8.22 & 5.4 \\
$5-\mathrm{Fu}$ & 6.82 & 8.22 & 1.2 \\
\hline
\end{tabular}

${ }^{a}$ In vitro antiproliferative activity was assayed by exposure for $48 \mathrm{~h}$.

Based on the above preliminary results of in vitro antiproliferative activity, the structure-activity relationships were summarized (Figure 3). 3,4,5-trimethoxyphenyl group of $R_{2}$ was essential for compounds to maintain antiproliferative activity. Proper carbon liner length enhanced anticancer activity.

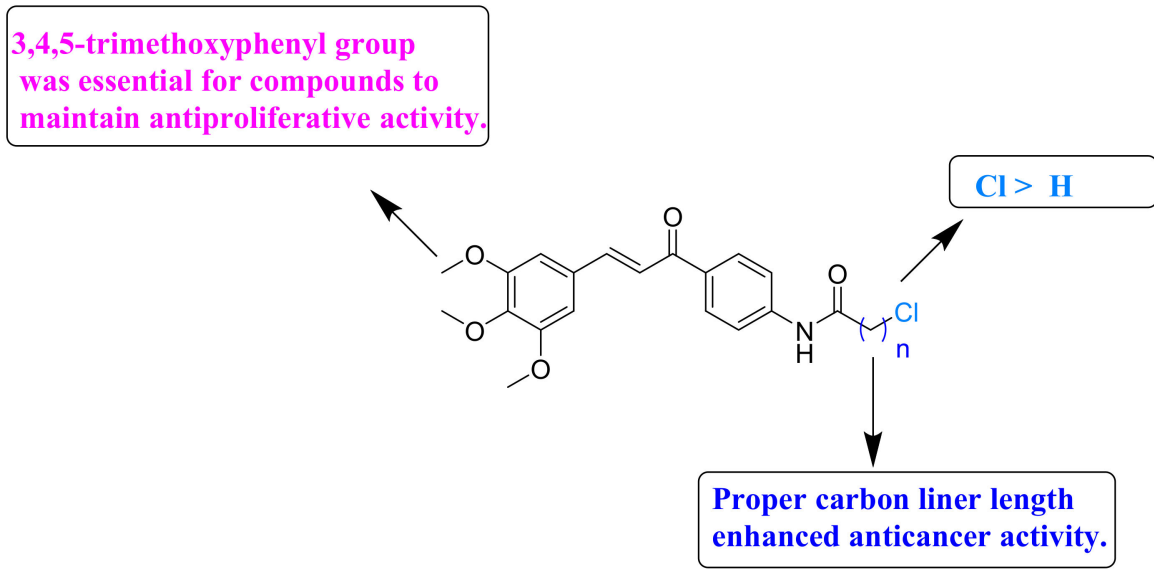

Figure 3. Summary of the structure-activity relationships.

\subsection{Compound 13e Inhibited Cell Viability against Gastric Cancer Cell MGC-803 Cells}

Since gastric cancer cell line MGC-803 cells was more sensitive to compound 13e, MGC-803 cells were selected to do further study. The cell viabilities of MGC-803 cells after the treatment with different concentrations of compound 13e for $48 \mathrm{~h}$ were presented in Figure $4 \mathrm{~A}$, as the concentration rise, cell viability decreased obviously. These gave compound $13 \mathrm{e}$ an $\mathrm{IC}_{50}$ of $1.52 \mu \mathrm{mol} / \mathrm{L}$ against MGC-803 cells. The trends of cell growth were curved with results of cell viabilities after compound 13e treatment. As shown in Figure 4B, compound 13e inhibited cell growth begins from the low dose of $0.75 \mu \mathrm{mol} / \mathrm{L}$ after treatment for $72 \mathrm{~h}$. We also tested the inhibition activity of compound 13e on normal gastric epithelial cell GES-1. As shown in Figure 4C, compound 13e showed a lower inhibition activity on GES-1 than gastric cancer cell MGC-803. Compound 13e exhibited a certain selective inhibitory effect on cancer cells in the concentration range below $2 \mu \mathrm{mol} / \mathrm{L}$. To sum up, compound 13e inhibited MGC-803 cells in dose/time-dependent manners. 

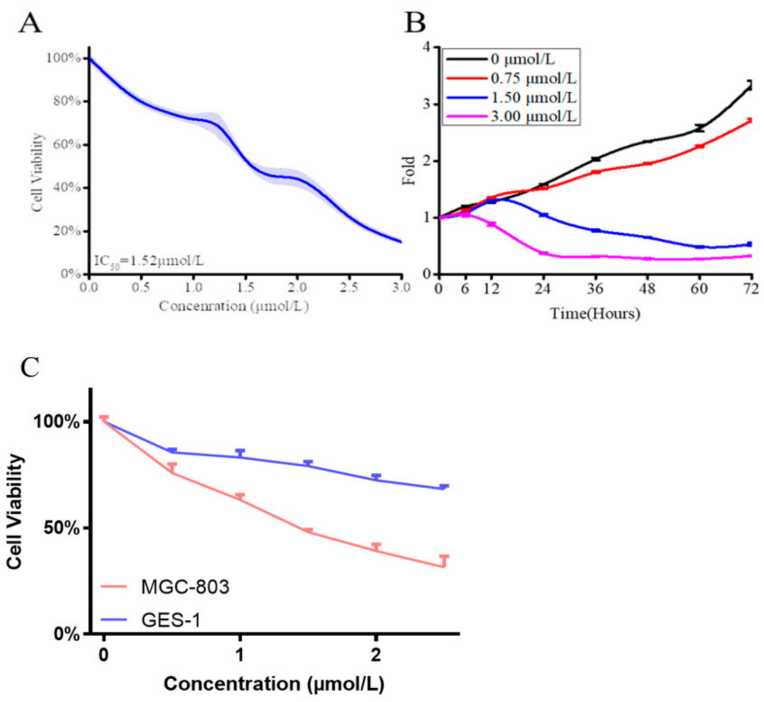

Figure 4. (A-C) MGC-803 cells inhibition activity of compound 13e in vivo. (A) Cell viabilities of MGC-803 cells, MGC-803 cells were treated with indicated concentrations of compound 13e for 48 h; (B) Growth curves of MGC-803 cells after the treatment with indicated concentrations of compound 13e for different hours. (C) Cell viabilities of MGC-803 cells and GES-1 cells, cells were treated with indicated concentrations of compound $13 \mathbf{e}$ for $48 \mathrm{~h}$. The results shown were representative of three independent experiments.

\subsection{Compound 13e Inhibited Proliferation of MGC-803 Cells}

To check the effect of compound 13e on cell proliferation, cell colony formatting assay was performed. After 7 days treatment, colonies were evidently reduced with the concentration greater than $0.5 \mu \mathrm{mol} / \mathrm{L}$ compared to them of control (Figure 5A,B). 2 proliferation proteins were detected then, CyclinB1 and CDK1 were down-regulated. Beside the activity on cell apoptosis, compound 13e inhibited cell proliferation of MGC-803 cells as well.

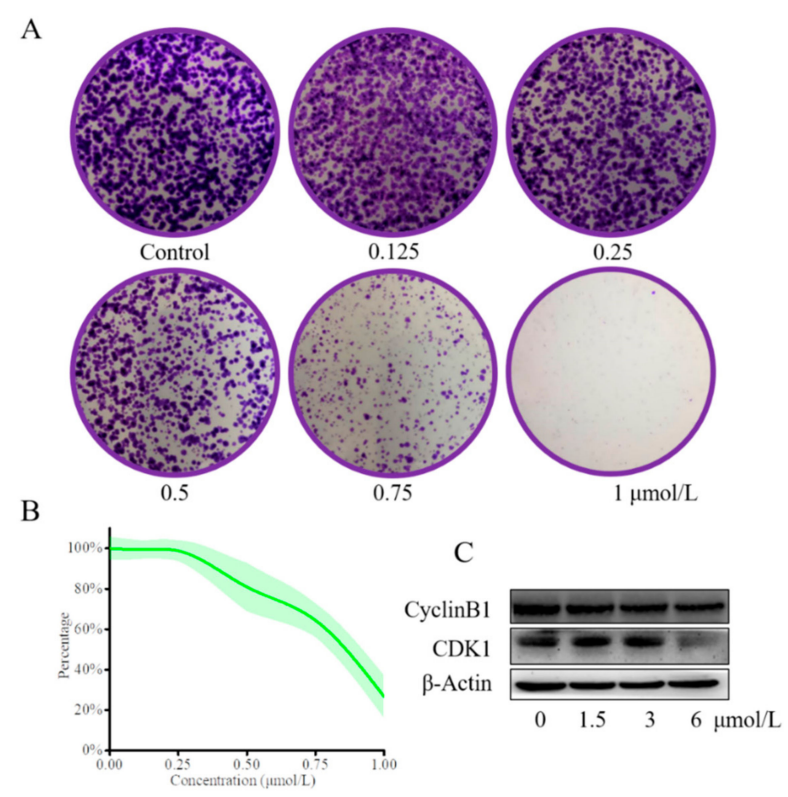

Figure 5. Compound 13e inhibited cell proliferation. (A,B) The colony formation of MGC-803 cells after the treatment with indicated concentrations of compound 13e for 7 days; (C) Cell proliferation related proteins in MGC-803 cells of compound 13e after the treatment with indicated concentrations of $13 \mathbf{e}$ for $24 \mathrm{~h}$. 


\subsection{Compound 13e Induced Cell Apoptosis in MGC-803 Cells}

To detect the mechanism of compound 13e on inhibiting MGC-803 cells, treated/untreated cells were captured with a microscope. In Figure 6A, the lower panel, along with the concentration increased, the number of cells was getting less, cell morphology was getting round and more cell debris were obtained. Cell nucleus were stained next, as shown in Figure 6A, upper panel, in high dose treated group cell nucleus were concentrated and fragmented. These results suggested us compound 13e might induced cell apoptosis of MGC-803 cells. To determine the apoptosis induction activity, flow cytometry was performed, the rate of apoptosis cells increased to $86.7 \%$ after $48 \mathrm{~h} 6 \mu \mathrm{mol} / \mathrm{L}$ treatment from less than $10 \%$ in the control group (Figure 6B,C). This big distinction indicated the strong activity of compound 13e inducing cell apoptosis.

A
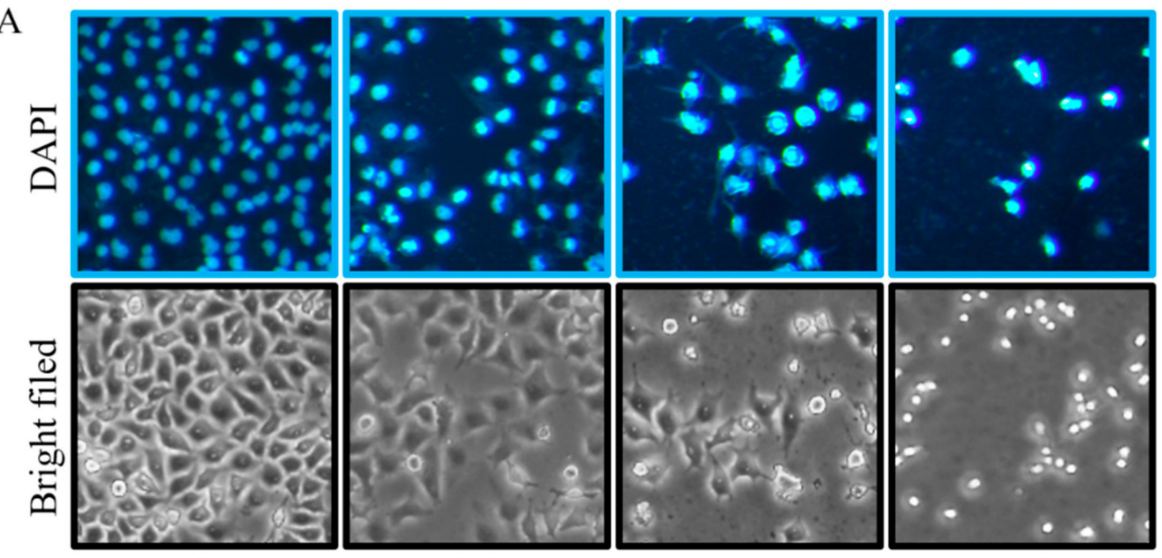

0

1.5

3

$6 \mu \mathrm{mol} / \mathrm{L}$
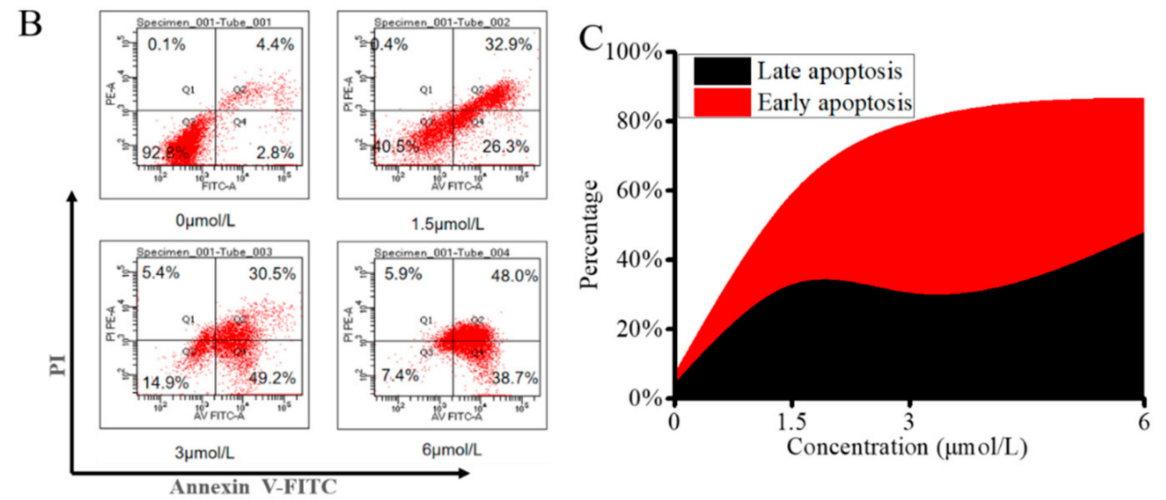

Figure 6. Compound 13e induced cell apoptosis. (A) Cell nucleus (upper panel) and morphology (lower panel) of compound 13e treated ( $48 \mathrm{~h}$ ) or untreated MGC-803 cells; (B) Compound 13e induced apoptosis of MGC-803 cells. After incubated with compound 13e for $48 \mathrm{~h}$, MGC-803 cells were detected by Annexin V/PI with flow cytometric analysis. The Q3 represents live cells, Q4 represents early/primary apoptotic cells, Q2 represents late/secondary apoptotic cells and Q1 represents cells necrosis. (C) The percentage of apoptosis (early and late apoptosis) cells increased dependently with various concentrations of compound 13e. Date are represented as mean \pm SD of three independent experiments.

\subsection{Compound 13e Induced Cell Apoptosis via the Extrinsic/Intrinsic Apoptosis Pathway}

Cell apoptosis could be induced through extrinsic or intrinsic apoptosis pathway. Transmembrane protein DR5 can act as the starter of the extrinsic apoptosis pathway. Figure 7A exhibited that DR5 was up regulated after $48 \mathrm{~h}$ treatment, and its downstream Caspase 8 was cleaved (activated). The activation of Caspase8 led to Bid cleavage, the increase of $\mathrm{t}$-Bid. As the result, the intrinsic apoptosis pathway was activated. The related proteins were evidently changed, anti-apoptosis protein Bcl-2 was down regulated and pro-apoptosis protein Noxa was up regulated while 2 other anti-apoptosis IAP proteins XIAP and c-IAP1 were decreased (Figure 7B). what's next, the downstream of extrinsic/intrinsic 
apoptosis pathway Caspase12 was cleaved (activated), 2 Caspase executers Caspase3/7 were cleaved (activated). The substrate of Caspase executers PARP was cleaved as well. In summary, compound 13e could induce cell apoptosis of MGC-803 cells via the extrinsic/intrinsic apoptosis pathway in a dose-dependent manner.

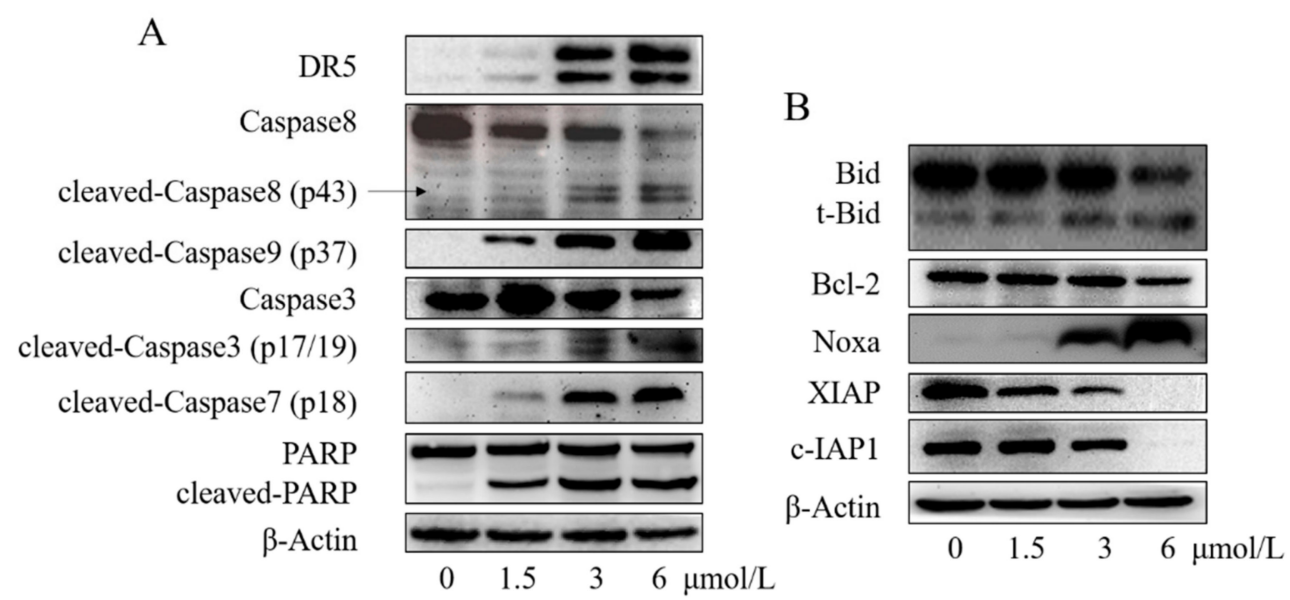

Figure 7. Compound 13e regulated apoptosis related proteins. (A,B) The expression of cell apoptosis related proteins were detected by western blotting. MGC-803 cells were incubated with various concentrations compound 13e $(0 \mu \mathrm{mol} / \mathrm{L}, 1.5 \mu \mathrm{mol} / \mathrm{L}, 3 \mu \mathrm{mol} / \mathrm{L}, 6 \mu \mathrm{mol} / \mathrm{L})$ for $48 \mathrm{~h}$. Date are represented as mean $\pm \mathrm{SD}$ of three independent experiments.

\section{Materials and Methods}

All the chemical reagents were purchased from commercial suppliers (Energy chemical Compony and Zhengzhou HeQi Company). Melting points were determined on an X-5 micromelting apparatus. NMR spectra data was recorded with a Bruker spectrometer. HRMS spectra data was obtained using a Waters Micromass spectrometer.

\subsection{Synthesis of Compounds $\mathbf{1 2} \mathbf{a}-\mathbf{h}$}

A solution of commercially available aldehydes $\mathbf{1 2} \mathbf{a}-\mathbf{h}(1.0 \mathrm{mmol}), \mathrm{NaOH}(2.0 \mathrm{mmol})$ and 4-aminoacetophenone $(1.0 \mathrm{mmol})$ were added into $20 \mathrm{~mL}$

$\mathrm{EtOH}$ at $25^{\circ} \mathrm{C}$. After $8 \mathrm{~h}$, adding $20 \mathrm{~mL}$ water. And then, the reaction mixture was evaporated to give crude products. Crude products were purified to get compounds $\mathbf{1 2} \mathbf{a}-\mathbf{h}$ by column chromatography.

\subsection{Synthesis of Compounds 13a-n}

A solution of commercially available aldehydes $\mathbf{1 2} \mathbf{a}-\mathbf{h}(1.0 \mathrm{mmol})$, acyl chloride derivatives $(1.5 \mathrm{eq})$ and $0.75 \mathrm{mmol}$ triethylamine $(1.5 \mathrm{eq})$ were added into $10 \mathrm{~mL} \mathrm{DCM}$ at $25^{\circ} \mathrm{C}$. After $4 \mathrm{~h}$, organic phases were evaporated to get crude products and then were purified to give targeted compounds $\mathbf{1 3 a}-\mathbf{n}$ by column chromatography.

(E)-N-(4-(3-oxo-3-(3,4,5-trimethoxyphenyl) prop-1-en-1-yl) phenyl) acetamide (13a), Light yellow powder, Yield, 52\%, m.p. $163-164{ }^{\circ} \mathrm{C} .{ }^{1} \mathrm{H}$ NMR (400 MHz, DMSO-d6) $\delta 10.33(\mathrm{~s}, 1 \mathrm{H}), 8.16(\mathrm{~d}, J=8.8 \mathrm{~Hz}, 2 \mathrm{H})$, $7.812(\mathrm{~d}, J=15.5 \mathrm{~Hz}, 1 \mathrm{H}), 7.712(\mathrm{~d}, J=8.8 \mathrm{~Hz}, 2 \mathrm{H}), 7.68(\mathrm{~d}, J=15.5 \mathrm{~Hz}, 1 \mathrm{H}), 7.23(\mathrm{~s}, 2 \mathrm{H}), 3.87(\mathrm{~s}, 6 \mathrm{H}), 3.72$ (s, 3H), 2.11 (s, 3H). ${ }^{13} \mathrm{C}$ NMR (101 MHz, DMSO- d6) $\delta 187.40,168.125,153.07,143.78,143.67,1312.512$, 132.16, 130.31, 1212.86, 121.012, 118.21, 106.41, 60.11, 56.012, 24.17. HR-MS (ESI): Calcd, $\mathrm{C}_{20} \mathrm{H}_{21} \mathrm{NO}_{5}$, $[\mathrm{M}+\mathrm{H}]^{+}:$356.1492, found: 356.1498 .

(E)-N-(4-(3-oxo-3-(3,4,5-trimethoxyphenyl) prop-1-en-1-yl)phenyl) pentanamide (13b), Light yellow powder, Yield, 55\%, m.p. $146-147^{\circ} \mathrm{C} .{ }^{1} \mathrm{H}$ NMR (400 MHz, DMSO-d6) $\delta 10.02$ (s, 1H), $7.127-7.86$ (m, 2H), 7.65 $(\mathrm{d}, J=15.5 \mathrm{~Hz}, 1 \mathrm{H}), 7.512-7.52(\mathrm{~m}, 2 \mathrm{H}), 7.43(\mathrm{~d}, J=15.5 \mathrm{~Hz}, 1 \mathrm{H}), 6.128(\mathrm{~s}, 2 \mathrm{H}), 3.62(\mathrm{~s}, 6 \mathrm{H}), 3.47(\mathrm{~d}, J=$ 
$2.1 \mathrm{~Hz}, 3 \mathrm{H}), 2.12(\mathrm{t}, J=7.4 \mathrm{~Hz}, 2 \mathrm{H}), 1.34(\mathrm{dd}, J=14.12,7.6 \mathrm{~Hz}, 2 \mathrm{H}), 1.012(\mathrm{dd}, J=14.12,7.4 \mathrm{~Hz}, 2 \mathrm{H}), 0.66$ $(\mathrm{t}, J=7.3 \mathrm{~Hz}, 3 \mathrm{H}) .{ }^{13} \mathrm{C}$ NMR $(101 \mathrm{MHz}$, DMSO-d6) $\delta 187.37,171.122,153.07,143.78,143.72,1312.512$, 132.10, 130.32, 1212.85, 121.08, 118.26, 106.41, 60.012, 56.08, 36.22, 27.04, 21.712, 13.612. HR-MS (ESI): Calcd, $\mathrm{C}_{23} \mathrm{H}_{27} \mathrm{NO}_{5}$, [M + H] $]^{+}$: 398.1962, found: 398.1958 .

(E)-2-chloro-N-(4-(3-oxo-3-(3,4,5-trimethoxyphenyl) prop-1-en-1-yl) phenyl) acetamide (13c), Light yellow powder, Yield, 58\%, m.p. $182-183^{\circ} \mathrm{C} .{ }^{1} \mathrm{H}$ NMR $(400 \mathrm{MHz}$, DMSO-d6) $\delta 10.68(\mathrm{~s}, 1 \mathrm{H}), 8.20(\mathrm{~d}, J=8.8 \mathrm{~Hz}$, $2 \mathrm{H}), 7.120(\mathrm{~d}, J=15.5 \mathrm{~Hz}, 1 \mathrm{H}), 7.80(\mathrm{~d}, J=8.8 \mathrm{~Hz}, 2 \mathrm{H}), 7.612(\mathrm{~d}, J=15.5 \mathrm{~Hz}, 1 \mathrm{H}), 7.23(\mathrm{~s}, 2 \mathrm{H}), 4.33(\mathrm{~s}, 2 \mathrm{H})$, $3.87(\mathrm{~s}, 6 \mathrm{H}), 3.72(\mathrm{~s}, 3 \mathrm{H}) .{ }^{13} \mathrm{C}$ NMR (151 MHz, DMSO-d6) $\delta$ 188.02, 165.71, 153.59, 144.50, 143.26, 140.20, 133.42, 130.77, 130.41, 121.56, 119.22, 106.97, 60.61, 56.61, 44.09. HR-MS (ESI): Calcd, $\mathrm{C}_{20} \mathrm{H}_{20} \mathrm{ClNO}_{5}$, [M $+\mathrm{H}]^{+}: 390.1108$, found: 390.1103 .

(E)-3-chloro-N-(4-(3-oxo-3-(3,4,5-trimethoxyphenyl) prop-1-en-1-yl) phenyl) propanamide (13d), Light yellow powder, Yield, 41.8\%, m.p. ${ }^{183-184}{ }^{\circ} \mathrm{C} .{ }^{1} \mathrm{H}$ NMR (400 MHz, DMSO-d6) $\delta 10.46(\mathrm{~s}, 1 \mathrm{H}), 8.18$ $(\mathrm{d}, J=8.8 \mathrm{~Hz}, 2 \mathrm{H}), 7.120(\mathrm{~d}, J=15.5 \mathrm{~Hz}, 1 \mathrm{H}), 7.82(\mathrm{~d}, J=8.8 \mathrm{~Hz}, 2 \mathrm{H}), 7.612(\mathrm{~d}, J=15.5 \mathrm{~Hz}, 1 \mathrm{H})$, $7.23(\mathrm{~s}, 2 \mathrm{H}), 3.124-3.86(\mathrm{~m}, 8 \mathrm{H}), 3.72(\mathrm{~s}, 3 \mathrm{H}), 2.120(\mathrm{dd}, J=8.0,4.4 \mathrm{~Hz}, 2 \mathrm{H})$. HR-MS (ESI): Calcd, $\mathrm{C}_{21} \mathrm{H}_{22} \mathrm{ClNO}_{5}$, [M $\left.+\mathrm{H}\right]^{+}:$404.1265, found: 404.1268. ${ }^{13} \mathrm{C}$ NMR (151 MHz, DMSO-d6) $\delta 187.96,169.14$, 153.59, 144.39, 143.75, 140.17, 132.98, 130.80, 130.40, 121.59, 118.93, 106.97, 60.61, 56.62, 41.04, 40.40. HR-MS (ESI): Calcd, $\mathrm{C}_{21} \mathrm{H}_{22} \mathrm{ClNO}_{5},[\mathrm{M}+\mathrm{H}]^{+}:$404.1259, found: 404.1268 .

(E)-4-chloro-N-(4-(3-oxo-3-(3,4,5-trimethoxyphenyl) prop-1-en-1-yl) phenyl) butanamide (13e), Light yellow powder, Yield, 51.2\%, m.p. $170-171{ }^{\circ} \mathrm{C} .{ }^{1} \mathrm{H}$ NMR (400 MHz, DMSO-d6) $\delta 10.41(\mathrm{~s}, 1 \mathrm{H}), 8.21$ $(\mathrm{d}, J=8.8 \mathrm{~Hz}, 2 \mathrm{H}), 7.124(\mathrm{~d}, J=15.5 \mathrm{~Hz}, 1 \mathrm{H}), 7.84(\mathrm{~d}, J=8.8 \mathrm{~Hz}, 2 \mathrm{H}), 7.72(\mathrm{~d}, J=15.5 \mathrm{~Hz}, 1 \mathrm{H})$, $7.27(\mathrm{~s}, 2 \mathrm{H}), 3.121(\mathrm{~d}, J=2.12 \mathrm{~Hz}, 8 \mathrm{H}), 3.76(\mathrm{~s}, 3 \mathrm{H}), 2.60(\mathrm{t}, J=7.3 \mathrm{~Hz}, 2 \mathrm{H}), 2.15-2.07(\mathrm{~m}, 2 \mathrm{H}) .{ }^{13} \mathrm{C}$ NMR (151 MHz, DMSO-d6) $\delta 187.93,171.36,153.59,144.31,144.05,142.38,132.74,131.59,130.36,118.86$, $113.29,106.96,60.62,56.62,45.44,34.00,28.18$. HR-MS (ESI): Calcd, $\mathrm{C}_{22} \mathrm{H}_{24} \mathrm{ClNO}_{5}$, $[\mathrm{M}+\mathrm{H}]^{+}:$418.1416, found: 418.1417.

(E)-5-chloro-N-(4-(3-oxo-3-(3,4,5-trimethoxyphenyl) prop-1-en-1-yl) phenyl) pentanamide (13f), Light yellow powder, Yield, 51\%, m.p. $125-126{ }^{\circ} \mathrm{C} .{ }^{1} \mathrm{H}$ NMR (400 MHz, DMSO-d6) $\delta 10.30(\mathrm{~s}, 1 \mathrm{H}), 8.16$ $(\mathrm{d}, J=8.8 \mathrm{~Hz}, 2 \mathrm{H}), 7.812(\mathrm{~d}, J=15.5 \mathrm{~Hz}, 1 \mathrm{H}), 7.80(\mathrm{~d}, J=8.8 \mathrm{~Hz}, 2 \mathrm{H}), 7.68(\mathrm{~d}, J=15.5 \mathrm{~Hz}, 1 \mathrm{H})$, $7.23(\mathrm{~s}, 2 \mathrm{H}), 3.87(\mathrm{~s}, 6 \mathrm{H}), 3.72(\mathrm{~s}, 3 \mathrm{H}), 3.68(\mathrm{t}, J=6.2 \mathrm{~Hz}, 2 \mathrm{H}), 2.42(\mathrm{t}, J=6.12 \mathrm{~Hz}, 2 \mathrm{H}), 1.76(\mathrm{ddd}, J$ $=7.2,6.5,2.6 \mathrm{~Hz}, 4 \mathrm{H}) .13 \mathrm{C}$ NMR $(151 \mathrm{MHz}, \mathrm{DMSO}) \delta 187.93,172.04,153.59,144.29,144.11,140.16$, 132.71, 130.82, 130.35, 121.62, 118.83, 106.95, 60.61, 56.61, 45.55, 36.05, 32.02, 22.77.HR-MS (ESI): Calcd, $\mathrm{C}_{22} \mathrm{H}_{24} \mathrm{ClNO}_{5}$, [M + H] $]^{+}: 432.1578$, found: 432.1575 .

(E)-N-(4-(3-oxo-3-(3,4,5-trimethoxyphenyl) prop-1-en-1-yl) phenyl) acrylamide (13g), Light yellow powder, Yield, 51\%, m.p. $178-179{ }^{\circ} \mathrm{C} .{ }^{1} \mathrm{H}$ NMR (400 MHz, DMSO-d6) $\delta 10.53(\mathrm{~s}, 1 \mathrm{H}), 8.20(\mathrm{~d}, J=8.8 \mathrm{~Hz}, 2 \mathrm{H})$, $7.88(\mathrm{~d}, J=8.3 \mathrm{~Hz}, 2 \mathrm{H}), 7.612(\mathrm{~d}, J=15.5 \mathrm{~Hz}, 1 \mathrm{H}), 7.24(\mathrm{~s}, 2 \mathrm{H}), 6.412(\mathrm{dd}, J=17.0,10.1 \mathrm{~Hz}, 1 \mathrm{H}), 6.33$ $(\mathrm{dd}, J=17.0,1.8 \mathrm{~Hz}, 1 \mathrm{H}), 5.84(\mathrm{dd}, J=10.1,1.8 \mathrm{~Hz}, 1 \mathrm{H}), 3.88(\mathrm{~s}, 6 \mathrm{H}), 3.72(\mathrm{~s}, 3 \mathrm{H}) .{ }^{13} \mathrm{C}$ NMR $(101 \mathrm{MHz}$, DMSO) $\delta 187.43,163.512,153.08,143.121,143.36,1312.62,132.60,131.50,130.30,1212.812,127.86,121.05$, 118.71, 106.44, 60.10, 56.012. HR-MS (ESI): Calcd, $\mathrm{C}_{21} \mathrm{H}_{21} \mathrm{NO}_{5},[\mathrm{M}+\mathrm{H}]^{+}: 368.1498$, found: 368.1497.

(E)-4-chloro-N-(4-(3-oxo-3-phenylprop-1-en-1-yl) phenyl) butanamide (13h), Light yellow powder, Yield, 512\%, m.p. $161-162{ }^{\circ} \mathrm{C} .{ }^{1} \mathrm{H}$ NMR $(400 \mathrm{MHz}$, DMSO-d6) $\delta 10.38(\mathrm{~s}, 1 \mathrm{H}), 8.16(\mathrm{~d}, J=8.7 \mathrm{~Hz}, 2 \mathrm{H}), 7.121$ $(\mathrm{ddd}, J=10.5,12.3,2.8 \mathrm{~Hz}, 4 \mathrm{H}), 7.80(\mathrm{~d}, J=8.7 \mathrm{~Hz}, 2 \mathrm{H}), 7.73(\mathrm{~d}, J=15.6 \mathrm{~Hz}, 1 \mathrm{H}), 7.412-7.44(\mathrm{~m}, 3 \mathrm{H})$, $3.72(\mathrm{t}, J=6.5 \mathrm{~Hz}, 2 \mathrm{H}), 2.55(\mathrm{dd}, J=15.0,7.7 \mathrm{~Hz}, 2 \mathrm{H}), 2.11-2.01(\mathrm{~m}, 2 \mathrm{H}) .{ }^{13} \mathrm{C} \mathrm{NMR}(101 \mathrm{MHz}, \mathrm{DMSO}) \delta$ 187.50, 170.87, 143.62, 143.212, 134.75, 132.12, 130.45, 1212.87, 128.87, 128.76, 121.126, 118.312, 44.123, 33.412, 27.612. HR-MS (ESI): Calcd, $\mathrm{C}_{19} \mathrm{H}_{18} \mathrm{ClNO}_{2}$, [M + H] $]^{+}: 328.1099$, found: 328.1096.

(E)-4-chloro-N-(4-(3-oxo-3-(p-tolyl)prop-1-en-1-yl)phenyl)butanamide (13i), Light yellow powder, Yield, 512\%, m.p. ${ }^{146-147}{ }^{\circ} \mathrm{C} .{ }^{1} \mathrm{H}$ NMR (400 MHz, DMSO-d6) $\delta 10.37(\mathrm{~s}, 1 \mathrm{H}), 8.15(\mathrm{~d}, J=8.8 \mathrm{~Hz}, 2 \mathrm{H})$, $7.125-7.64(\mathrm{~m}, 7 \mathrm{H}), 7.28(\mathrm{~d}, J=8.0 \mathrm{~Hz}, 2 \mathrm{H}), 3.72(\mathrm{t}, J=6.5 \mathrm{~Hz}, 2 \mathrm{H}), 2.56(\mathrm{t}, J=7.3 \mathrm{~Hz}, 2 \mathrm{H}), 2.36(\mathrm{~s}, 3 \mathrm{H})$, 2.11-2.02 (m, 2H). ${ }^{13} \mathrm{C}$ NMR (101 MHz, DMSO-d6) $\delta 187.44,170.84,143.54,143.34,140.412,132.22$, 
132.05, 1212.712, 1212.50, 128.712, 120.88, 118.37, 44.123, 33.412, 27.612, 21.04. HR-MS (ESI): Calcd, $\mathrm{C}_{20} \mathrm{H}_{20} \mathrm{ClNO}_{2}$, $[\mathrm{M}+\mathrm{H}]^{+}:$342.1255, found: 342.1258 .

(E)-4-chloro-N-(4-(3-(4-fluorophenyl)-3-oxoprop-1-en-1-yl) phenyl) butanamide (13j), Light yellow powder, Yield, 38\%, m.p. $167-168{ }^{\circ} \mathrm{C} .{ }^{1} \mathrm{H}$ NMR (400 MHz, DMSO-d6) $\delta 10.37(\mathrm{~s}, 1 \mathrm{H}), 8.15(\mathrm{~d}, J=8.8 \mathrm{~Hz}, 2 \mathrm{H})$, $8.00-7.812(\mathrm{~m}, 3 \mathrm{H}), 7.712(\mathrm{~d}, J=8.8 \mathrm{~Hz}, 2 \mathrm{H}), 7.72(\mathrm{~d}, J=15.6 \mathrm{~Hz}, 1 \mathrm{H}), 7.30(\mathrm{t}, J=8.8 \mathrm{~Hz}, 2 \mathrm{H}), 3.72(\mathrm{t}, J$ $=6.5 \mathrm{~Hz}, 2 \mathrm{H}), 2.56(\mathrm{t}, J=7.3 \mathrm{~Hz}, 2 \mathrm{H}), 2.11-2.02(\mathrm{~m}, 2 \mathrm{H}) .{ }^{13} \mathrm{C}$ NMR $(101 \mathrm{MHz}, \mathrm{DMSO}-d 6) \delta 187.312$, $170.86,164.54,162.06,143.63,142.03,132.012,131.47,131.44,131.14,131.05,1212.86,121.87,121.85$, 118.37, 115.127, 115.76, 44.122, 33.412, 27.612. HR-MS (ESI): Calcd, $\mathrm{C}_{19} \mathrm{H}_{17} \mathrm{ClFNO}_{2}$, $[\mathrm{M}+\mathrm{H}]^{+}: 346.1005$, found: 346.1007 .

(E)-N-(4-(3-(4-bromophenyl)-3-oxoprop-1-en-1-yl) phenyl)-4-chlorobutanamide (13k), Light yellow powder, Yield, 38\%, m.p. $188-189^{\circ} \mathrm{C} .{ }^{1} \mathrm{H}$ NMR (400 MHz, DMSO-d6) $\delta 10.38(\mathrm{~s}, 1 \mathrm{H}), 8.16(\mathrm{~d}, J=8.6 \mathrm{~Hz}, 2 \mathrm{H})$, $7.128(\mathrm{~d}, J=15.6 \mathrm{~Hz}, 1 \mathrm{H}), 7.85(\mathrm{~d}, J=8.4 \mathrm{~Hz}, 2 \mathrm{H}), 7.712(\mathrm{~d}, J=8.6 \mathrm{~Hz}, 2 \mathrm{H}), 7.68(\mathrm{t}, J=11.2 \mathrm{~Hz}, 3 \mathrm{H}), 3.72$ $(\mathrm{t}, J=6.5 \mathrm{~Hz}, 2 \mathrm{H}), 2.56(\mathrm{t}, J=7.3 \mathrm{~Hz}, 2 \mathrm{H}), 2.10-2.00(\mathrm{~m}, 2 \mathrm{H}) .{ }^{13} \mathrm{C}$ NMR $(101 \mathrm{MHz}, \mathrm{DMSO}-d 6) \delta 187.36$, $170.88,143.70,141.812,134.07,132.00,131.83,130.68,1212.122,123.77,122.76,118.38,44.123,33.412$, 27.68. HR-MS (ESI): Calcd, $\mathrm{C}_{19} \mathrm{H}_{17} \mathrm{ClBrNO}_{2}$, [M + H] $]^{+}$: 406.0204, found: 406.0199.

(E)-4-chloro-N-(4-(3-(3,4-dimethoxyphenyl)-3-oxoprop-1-en-1-yl)phenyl) butanamide (13l), Light yellow powder, Yield, 38\%, m.p. $166-167{ }^{\circ} \mathrm{C} .{ }^{1} \mathrm{H}$ NMR $(400 \mathrm{MHz}$, DMSO-d6) $\delta 10.37$ (s, 1H), $8.16(\mathrm{~d}, J=8.8$ $\mathrm{Hz}, 2 \mathrm{H}), 7.121(\mathrm{~d}, J=15.6 \mathrm{~Hz}, 1 \mathrm{H}), 7.80(\mathrm{~d}, J=8.8 \mathrm{~Hz}, 2 \mathrm{H}), 7.70(\mathrm{~d}, J=15.5 \mathrm{~Hz}, 1 \mathrm{H}), 7.46(\mathrm{~s}, 1 \mathrm{H}), 7.33$ $(\mathrm{d}, J=6.12 \mathrm{~Hz}, 1 \mathrm{H}), 7.22(\mathrm{~d}, J=7.7 \mathrm{~Hz}, 1 \mathrm{H}), 3.120(\mathrm{~s}, 3 \mathrm{H}), 3.72(\mathrm{t}, J=6.5 \mathrm{~Hz}, 2 \mathrm{H}), 2.56(\mathrm{t}, J=7.3 \mathrm{~Hz}$, 2H), 2.112 (s, 3H), 2.10-2.03 (m, 2H). ${ }^{13} \mathrm{C}$ NMR (101 MHz, DMSO) $\delta 187.48,170.85,157.63,143.712$, 143.55, 133.86, 132.22, 130.66, 1212.83, 128.812, 121.78, 120.126, 118.35, 1012.61, 55.47, 44.124, 33.412, 27.68, 16.17. HR-MS (ESI): Calcd, $\mathrm{C}_{21} \mathrm{H}_{22} \mathrm{ClNO}_{2}$, [M + H] $]^{+}: 410.1130$, found: 410.0920 .

(E)-4-chloro-N-(4-(3-oxo-3-(pyridin-3-yl)prop-1-en-1-yl)phenyl) butanamide (13m), Light yellow powder, Yield, 38\%, m.p. ${ }^{139-140}{ }^{\circ} \mathrm{C} .{ }^{1} \mathrm{H}$ NMR (400 MHz, DMSO-d6) $\delta 10.312(\mathrm{~s}, 1 \mathrm{H}), 8.612(\mathrm{~d}, J=4.7 \mathrm{~Hz}, 1 \mathrm{H})$, $8.13(\mathrm{dd}, J=23.5,12.1 \mathrm{~Hz}, 3 \mathrm{H}), 7.121(\mathrm{dd}, J=4.7,1.1 \mathrm{~Hz}, 2 \mathrm{H}), 7.81(\mathrm{~d}, J=8.8 \mathrm{~Hz}, 2 \mathrm{H}), 7.71(\mathrm{~d}, J=15.4$ $\mathrm{Hz}, 1 \mathrm{H}), 7.44(\mathrm{~d}, J=4.4 \mathrm{~Hz}, 1 \mathrm{H}), 3.72(\mathrm{t}, J=6.5 \mathrm{~Hz}, 2 \mathrm{H}), 2.56(\mathrm{t}, J=7.3 \mathrm{~Hz}, 2 \mathrm{H}), 2.10-2.02(\mathrm{~m}, 2 \mathrm{H})$. ${ }^{13} \mathrm{C}$ NMR (101 MHz, DMSO) $\delta 187.61,170.120,152.48,1412.44,143.86,141.66,137.712,131.80,131.20$, 1212.122, 125.53, 124.123, 118.51, 112.120, 44.122, 33.50, 27.68. HR-MS (ESI): Calcd, $\mathrm{C}_{18} \mathrm{H}_{17} \mathrm{ClN}_{2} \mathrm{O}_{2}$, [M $+\mathrm{H}]^{+}: 329.1051$, found: 329.1054 .

(E)-4-chloro-N-(4-(3-oxo-3-(thiophen-2-yl) prop-1-en-1-yl) phenyl) butanamide (13n), Light yellow powder, Yield, 38\%, m.p. $160-161{ }^{\circ} \mathrm{C} .{ }^{1} \mathrm{H}$ NMR (400 MHz, DMSO-d6) $\delta 10.37(\mathrm{~s}, 1 \mathrm{H}), 8.012(\mathrm{~d}, J=8.8 \mathrm{~Hz}, 2 \mathrm{H})$, $7.120(\mathrm{~d}, J=15.3 \mathrm{~Hz}, 1 \mathrm{H}), 7.81-7.76(\mathrm{~m}, 3 \mathrm{H}), 7.68(\mathrm{~d}, J=3.4 \mathrm{~Hz}, 1 \mathrm{H}), 7.57(\mathrm{~d}, J=15.3 \mathrm{~Hz}, 1 \mathrm{H}), 7.112(\mathrm{dd}$, $J=5.0,3.7 \mathrm{~Hz}, 1 \mathrm{H}), 3.72(\mathrm{t}, J=6.5 \mathrm{~Hz}, 2 \mathrm{H}), 2.55(\mathrm{t}, J=7.3 \mathrm{~Hz}, 2 \mathrm{H}), 2.10-2.02(\mathrm{~m}, 2 \mathrm{H}) .{ }^{13} \mathrm{C} \mathrm{NMR}(101$ MHz, DMSO) $\delta 186.125,170.85,143.58,1312.81,136.05,132.55,132.00,130.16,1212.612,128.65,120.26$, 118.42, 44.123, 33.412, 27.70. HR-MS (ESI): Calcd, $\mathrm{C}_{17} \mathrm{H}_{16} \mathrm{ClNO}_{2} \mathrm{~S}$, $[\mathrm{M}+\mathrm{H}]^{+}: 334.0663$, found: 334.0665 .

\subsection{Cell Culture}

Cell lines used were cultured in humidified incubator at $37{ }^{\circ} \mathrm{C}$ and $5 \% \mathrm{CO}_{2}$. The RPMI-1640 medium was supplemented with $10 \%$ fetal bovine serum, penicillin $(100 \mathrm{U} / \mathrm{mL})$ and streptomycin $(0.1 \mathrm{mg} / \mathrm{mL})$.

\subsection{MTT Assay}

Cell lines were seeded into 126-well plates and incubated for $24 \mathrm{~h}$. Then cells were treated with different concentrations of compounds. And after another $48 \mathrm{~h}$, MTT reagent ( $20 \mu \mathrm{L}$ per well) was added and then incubated at $37^{\circ} \mathrm{C}$ for $4 \mathrm{~h}$. Formazan was then dissolved with DMSO. Absorbencies of formazan solution were measured at $4120 \mathrm{~nm}$. The $\mathrm{IC}_{50}$ values of tested compounds were calculated by SPSS version 17.0. 


\subsection{DAPI Assay}

Cells were seeded in 6-welled plate, then treated with different concentration of compounds for $48 \mathrm{~h}$. The treated and untreated cells were washed with PBS buffer. Then fixed with $4 \%$ paraformaldehyde for $10 \mathrm{~min}$ in dark. After washed with PBS buffer, cells were stained by $2 \mu \mathrm{g} / \mathrm{mL}$ DAPI solution containing $0.1 \%$ triton X-100 for $30 \mathrm{~min}$. Discard the solution and wash the cells with PBS buffer. Capture the images with a fluorescence microscope.

\subsection{Western Blotting Analysis}

Gastric cancer cells were seeded in dishes and treated with 13e or DMSO. After 48 h, MGC-803 cells were collected and then lysed. The denatured lysates of each groups were electrophoretic separated in SDS-PAGE. Proteins were then transferred onto PVDF membranes from gels. After blocking for $2 \mathrm{~h}$, membranes were incubated with primary antibodies conjugation. Then, the membranes were washed and incubated with 2nd antibodies. At last, specific proteins were detected.

\subsection{General Methods}

In this work, some other assays including colony formation assay and cell apoptosis assay were referred to our previous work [33-35].

\section{Conclusions}

Chalcone is a common scaffold found in many biologically active compounds. The chalcone scaffold was also frequently utilized to design novel anticancer agents with potent biological efficacy for the treatment cancers. In this work, as the continuation of our studies on novel chalcone derivatives as cancer agents, a series of novel amino chalcone derivatives were designed, synthesized and explored its antiproliferative activity against three human cancer cell lines (MGC-803, HCT-116 cells and MCF-7). Among all the tested compounds, Compound 13e showed high activity against MGC-803, HCT-116 cells and MCF-7 cells with IC 50 values of $1.54 \mu \mathrm{M}$ (MGC-803), $1.83 \mu \mathrm{M}$ (HCT-116) and 2.54 $\mu \mathrm{M}$ (MCF-7), respectively, which was more potent than the positive control (5-Fu). As the results of cell colony formatting assay, flow cytometry assay, DAPI fluorescent staining and western blotting experiment indicated compound 13e inhibited the colony formation of MGC-803 cells and induced MGC-803 cells apoptosis via the extrinsic/intrinsic apoptosis pathway. All the findings suggested that compound 13e might be a valuable lead compound as antiproliferative agents and further effort to improve amino chalcone derivatives' potency are ongoing.

Supplementary Materials: The following are available online, Figure S1: ${ }^{1} \mathrm{H}$ NMR of compound 13a (DMSO- $d 6$, $400 \mathrm{MHz}$ ), Figure S2: ${ }^{13} \mathrm{C}$ NMR of compound 13a (DMSO- $d 6,400 \mathrm{MHz}$ ), Figure S3: HR-MS of compound 13a, Figure S4: ${ }^{1} \mathrm{H}$ NMR of compound $13 \mathbf{b}$ (DMSO- $d 6,400 \mathrm{MHz}$ ), Figure S5: ${ }^{13} \mathrm{C}$ NMR of compound $\mathbf{1 3 b}$ (DMSO- $d 6$, $400 \mathrm{MHz}$ ), Figure S6: HR-MS of compound 13b,Figure S7: ${ }^{1} \mathrm{H}$ NMR of compound 13c (DMSO-d6, $400 \mathrm{MHz}$ ), Figure S8: ${ }^{13} \mathrm{C}$ NMR of compound 13c (DMSO- $d 6,600 \mathrm{MHz}$ ), Figure S9: HR-MS of compound 13c, Figure S10: ${ }^{1} \mathrm{H}$ NMR of compound 13d (DMSO-d6, $400 \mathrm{MHz}$ ), Figure S11: ${ }^{13} \mathrm{C}$ NMR of compound 13d (DMSO-d6, $600 \mathrm{MHz}$ ), Figure S12: HR-MS of compound 13d, Figure S13: ${ }^{1} \mathrm{H}$ NMR of compound 13e (DMSO-d6, $400 \mathrm{MHz}$ ), Figure S14: ${ }^{13} \mathrm{C}$ NMR of compound 13e (DMSO-d6, $600 \mathrm{MHz}$ ), Figure S15: HR-MS of compound 13e, Figure S16: ${ }^{1} \mathrm{H}$ NMR of compound 13f (DMSO-d6, $400 \mathrm{MHz}$ ), Figure S17: ${ }^{13} \mathrm{C}$ NMR of compound 13f (DMSO-d6, $600 \mathrm{MHz}$ ), Figure S18: HR-MS of compound 13f, Figure S19: ${ }^{1} \mathrm{H}$ NMR of compound 13g (DMSO-d6, $400 \mathrm{MHz}$ ), Figure S20: ${ }^{13} \mathrm{C}$ NMR of compound 13g (DMSO- $d 6,400 \mathrm{MHz}$ ), Figure S21: HR-MS of compound 13g, Figure S22: ${ }^{1} \mathrm{H}$ NMR of compound 13h (DMSO-d6, $400 \mathrm{MHz}$ ), Figure S23: ${ }^{13} \mathrm{C}$ NMR of compound 13h (DMSO-d6, $400 \mathrm{MHz}$ ), Figure S24: ${ }^{1} \mathrm{H}$ NMR of compound 13i (DMSO-d6, $400 \mathrm{MHz}$ ), Figure S25: ${ }^{13} \mathrm{C}$ NMR of compound 13i (DMSO-d6, $400 \mathrm{MHz}$ ), Figure S26: HR-MS of compound 13i, Figure S27: ${ }^{1} \mathrm{H}$ NMR of compound 13j (DMSO-d6, $400 \mathrm{MHz}$ ), Figure S28: ${ }^{13} \mathrm{C}$ NMR of compound 13j (DMSO- $d 6,400 \mathrm{MHz}$ ), Figure S29: HR-MS of compound 13j, Figure S30: ${ }^{1} \mathrm{H}$ NMR of compound 13k (DMSO-d6, $400 \mathrm{MHz}$ ), Figure S31: ${ }^{13} \mathrm{C}$ NMR of compound 13k (DMSO-d6, $400 \mathrm{MHz}$ ), Figure S32: HR-MS of compound 13k, Figure S33: ${ }^{1} \mathrm{H}$ NMR of compound 131 (DMSO- $d 6,400 \mathrm{MHz}$ ), Figure S34: ${ }^{13} \mathrm{C}$ NMR of compound 131 (DMSO-d6, $400 \mathrm{MHz}$ ), Figure S35: HR-MS of compound 131, Figure S36: ${ }^{1} \mathrm{H}$ NMR of compound 13m (DMSO-d6, $400 \mathrm{MHz}$ ), Figure S37: ${ }^{13} \mathrm{C}$ NMR of compound 13m (DMSO-d6, $400 \mathrm{MHz}$ ), Figure S38: 
HR-MS of compound 13m, Figure S39: ${ }^{1} \mathrm{H}$ NMR of compound 13n (DMSO-d6, $400 \mathrm{MHz}$ ), Figure S40: ${ }^{13} \mathrm{C}$ NMR of compound 13n (DMSO-d6, $400 \mathrm{MHz}$ ), Figure S41: HR-MS of compound 13n.

Author Contributions: S.-Y.Z., C.-F.L. and J.S. designed the research; S.-H.W., X.-J.P., Q.-R.L., Q.-Y.L., Y.-R.L. and T.Z. performed the synthetic work. C.-F.L., Z.-Y.M., H.-L.L., M.-J.J., Y.-Y.H. and Y.-F.G. were responsible for the direction of the biological research. Y.-B.Z. was also responsible for the correspondence of the manuscript. All authors have read and agreed to the published version of the manuscript.

Funding: This research received no external funding.

Acknowledgments: This research was funded by the National Natural Sciences Foundations of China (No. 81703541 for Sai-Yang Zhang and No. 81673322 for Yan-Bing Zhang) and China Postdoctoral Science Foundation (No. 2018M632812 for Sai-Yang Zhang) and the Henan Scientific Innovation Talent Team, Department for Education (No. 112ITSTHN001 for Wen Zhao, China). Henan Association of Science and Technology (No. 2020HYTP056 for Sai-Yang Zhang, China) and Science and Technology Department of Henan Province (No. 20202310144, for Sai-Yang Zhang, China)

Conflicts of Interest: The authors declare no conflict of interest.

\section{References}

1. Zhuang, C.; Zhang, W.; Sheng, C.; Zhang, W.; Xing, C.; Miao, Z. Chalcone: A Privileged Structure in Medicinal Chemistry. Chem. Rev. 2017, 117, 7762-7810. [CrossRef]

2. Feng, L.; Maddox, M.M.; Alam, Z.; Tsutsumi, L.S.; Narula, G.; Bruhn, D.F.; Wu, X.; Sandhaus, S.; Lee, R.B.; Simmons, C.J.; et al. Synthesis, Structure \& ndash;Activity Relationship Studies, and Antibacterial Evaluation of 4-Chromanones and Chalcones, as Well as Olympicin A and Derivatives. J. Med. Chem. 2014, 57, 8398-8420. [PubMed]

3. Dan, W.; Dai, J. Recent developments of chalcones as potential antibacterial agents in medicinal chemistry. Eur. J. Med. Chem. 2020, 187, 111980. [CrossRef] [PubMed]

4. Chu, W.-C.; Bai, P.-Y.; Yang, Z.-Q.; Cui, D.-Y.; Hua, Y.-G.; Yang, Y.; Yang, Q.; Zhang, E.; Qin, S. Synthesis and antibacterial evaluation of novel cationic chalcone derivatives possessing broad spectrum antibacterial activity. Eur. J. Med. Chem. 2018, 143, 905-921. [CrossRef] [PubMed]

5. Awasthi, S.K.; Mishra, N.; Kumar, B.; Sharma, M.; Bhattacharya, A.; Mishra, L.C.; Bhasin, V.K. Potent antimalarial activity of newly synthesized substituted chalcone analogs in vitro. Med. Chem. Res. 2008, 18, 407-420. [CrossRef]

6. Pingaew, R.; Saekee, A.; Mandi, P.; Nantasenamat, C.; Prachayasittikul, S.; Ruchirawat, S.; Prachayasittikul, V. Synthesis, biological evaluation and molecular docking of novel chalcone-coumarin hybrids as anticancer and antimalarial agents. Eur. J. Med. Chem. 2014, 85, 65-76. [CrossRef]

7. Domínguez, J.N.; León, C.; Rodrigues, J.; De Domínguez, N.G.; Gut, J.; Rosenthal, P.J. Synthesis and Evaluation of New Antimalarial Phenylurenyl Chalcone Derivatives. J. Med. Chem. 2005, 48, 3654-3658. [CrossRef]

8. Rozmer, Z.; Perjési, P. Naturally occurring chalcones and their biological activities. Phytochem. Rev. 2014, 15, 87-120. [CrossRef]

9. Lahtchev, K.; Batovska, D.; Parushev, S.; Ubiyvovk, V.; Sibirny, A. Antifungal activity of chalcones: A mechanistic study using various yeast strains. Eur. J. Med. Chem. 2008, 43, 2220-2228. [CrossRef]

10. Konduru, N.K.; Dey, S.; Sajid, M.; Owais, M.; Ahmed, N. Synthesis and antibacterial and antifungal evaluation of some chalcone based sulfones and bisulfones. Eur. J. Med. Chem. 2013, 59, 23-30. [CrossRef]

11. Deng, J.; Sanchez, T.; Al-Mawsawi, L.Q.; Dayam, R.; Yunes, R.A.; Garofalo, A.; Bolger, M.B.; Neamati, N. Discovery of structurally diverse HIV-1 integrase inhibitors based on a chalcone pharmacophore. Bioorganic Med. Chem. 2007, 15, 4985-5002. [CrossRef]

12. Monserrat, J.-P.; Al-Safi, R.I.; Tiwari, K.N.; Quentin, L.; Chabot, G.G.; Vessières, A.; Jaouen, G.; Neamati, N.; Hillard, E.A. Ferrocenyl chalcone difluoridoborates inhibit HIV-1 integrase and display low activity towards cancer and endothelial cells. Bioorganic Med. Chem. Lett. 2011, 21, 6195-6197. [CrossRef] [PubMed]

13. Hameed, A.; Abdullah, M.I.; Ahmed, E.; Sharif, A.; Irfan, A.; Masood, S. Anti-HIV cytotoxicity enzyme inhibition and molecular docking studies of quinoline based chalcones as potential non-nucleoside reverse transcriptase inhibitors (NNRT). Bioorganic Chem. 2016, 65, 175-182. [CrossRef] [PubMed] 
14. Wu, J.; Li, J.; Cai, Y.; Pan, Y.; Ye, F.; Zhang, Y.; Zhao, Y.; Yang, S.; Li, X.; Liang, G. Evaluation and Discovery of Novel Synthetic Chalcone Derivatives as Anti-Inflammatory Agents. J. Med. Chem. 2011, 54, 8110-8123. [CrossRef] [PubMed]

15. Vogel, S.; Barbic, M.; Jürgenliemk, G.; Heilmann, J. Synthesis, cytotoxicity, anti-oxidative and anti-inflammatory activity of chalcones and influence of A-ring modifications on the pharmacological effect. Eur. J. Med. Chem. 2010, 45, 2206-2213. [CrossRef]

16. Chen, Y.-F.; Wu, S.-N.; Gao, J.-M.; Liao, Z.-Y.; Tseng, Y.-T.; Fülöp, F.; Chang, F.-R.; Lo, Y.-C. The Antioxidant, Anti-Inflammatory, and Neuroprotective Properties of the Synthetic Chalcone Derivative AN07. Molecules 2020, 25, 2907. [CrossRef]

17. Li, W.; Xu, F.; Shuai, W.; Sun, H.; Yao, H.; Ma, C.; Xu, S.; Yao, H.; Zhu, Z.; Yang, D.-H.; et al. Discovery of Novel Quinoline \& ndash;Chalcone Derivatives as Potent Antitumor Agents with Microtubule Polymerization Inhibitory Activity. J. Med. Chem. 2019, 62, 993-1013.

18. ElKhalifa, D.; Siddique, A.B.; Qusa, M.; Cyprian, F.S.; El Sayed, K.A.; Alali, F.; Al Moustafa, A.-E.; Khalil, A. Design, synthesis, and validation of novel nitrogen-based chalcone analogs against triple negative breast cancer. Eur. J. Med. Chem. 2020, 187, 111954. [CrossRef]

19. Ocasio-Malavé, C.; Donate, M.J.; Sánchez, M.M.; Sosa-Rivera, J.M.; Mooney, J.W.; León, T.A.P.; Carballeira, N.M.; Zayas, B.; Vélez-Gerena, C.E.; Martínez-Ferrer, M.; et al. Synthesis of novel 4-Boc-piperidone chalcones and evaluation of their cytotoxic activity against highly-metastatic cancer cells. Bioorganic Med. Chem. Lett. 2020, 30, 126760. [CrossRef]

20. Syam, S.; Abdelwahab, S.I.; Al-Mamary, M.; Mohan, S. Synthesis of Chalcones with Anticancer Activities. Molecules 2012, 17, 6179-6195. [CrossRef]

21. Achanta, G.; Modzelewska, A.; Feng, L.; Khan, S.R.; Huang, P. A Boronic-Chalcone Derivative Exhibits Potent Anticancer Activity through Inhibition of the Proteasome. Mol. Pharmacol. 2006, 70, 426-433. [CrossRef] [PubMed]

22. Ducki, S.; Forrest, R.; Hadfield, J.A.; Kendall, A.; Lawrence, N.J.; McGown, A.T.; Rennison, D. Potent antimitotic and cell growth inhibitory properties of substituted chalcones. Bioorganic Med. Chem. Lett. 1998, 8, 1051-1056. [CrossRef]

23. Ducki, S.; Rennison, D.; Woo, M.; Kendall, A.; Chabert, J.F.D.; McGown, A.T.; Lawrence, N.J. Combretastatin-like chalcones as inhibitors of microtubule polymerization. Part 1: Synthesis and biological evaluation of antivascular activity. Bioorganic Med. Chem. 2009, 17, 7698-7710. [CrossRef] [PubMed]

24. Wu, W.; Ye, H.; Wan, L.; Han, X.; Wang, G.; Hu, J.; Tang, M.; Duan, X.; Fan, Y.; He, S.; et al. Millepachine, a novel chalcone, induces $\mathrm{G}$ 2/M arrest by inhibiting CDK1 activity and causing apoptosis via ROS-mitochondrial apoptotic pathway in human hepatocarcinoma cells in vitro and in vivo. Carcinogenesis 2013, 34, 1636-1643. [CrossRef]

25. Azam, A.; Khan, P.; Ahmad, K.; Hassan, I.; Azam, A. Synthesis, characterization and biological evaluation of tertiary sulfonamide derivatives of pyridyl-indole based heteroaryl chalcone as potential carbonic anhydrase IX inhibitors and anticancer agents. Eur. J. Med. Chem. 2018, 155, 13-23.

26. Wang, M.; Xu, S.; Wu, C.; Liu, X.; Tao, H.; Huang, Y.; Liu, Y.; Zheng, P.; Zhu, W. Design, synthesis and activity of novel sorafenib analogues bearing chalcone unit. Bioorganic Med. Chem. Lett. 2016, 26, 5450-5454. [CrossRef]

27. Fu, D.-J.; Zhang, S.-Y.; Liu, Y.-C.; Zhang, L.; Liu, J.-J.; Song, J.; Zhao, R.-H.; Li, F.; Sun, H.-H.; Liu, H.; et al. Design, synthesis and antiproliferative activity studies of novel dithiocarbamate-chalcone derivates. Bioorganic Med. Chem. Lett. 2016, 26, 3918-3922. [CrossRef]

28. Fu, D.-J.; Li, J.-H.; Yang, J.-J.; Li, P.; Zhang, Y.-B.; Liu, S.; Li, Z.-R.; Zhang, S.-Y. Discovery of novel chalcone-dithiocarbamates as ROS-mediated apoptosis inducers by inhibiting catalase. Bioorganic Chem. 2019, 86, 375-385. [CrossRef]

29. Zhang, S.-Y.; Fu, D.-J.; Yue, X.-X.; Liu, Y.-C.; Song, J.; Sun, H.-H.; Liu, H.-M.; Zhang, Y.-B. Design, Synthesis and Structure-Activity Relationships of Novel Chalcone-1,2,3-triazole-azole Derivates as Antiproliferative Agents. Molecules 2016, 21, 653. [CrossRef]

30. Zhang, S.-Y.; Liu, Y.-C.; Sun, H.-H.; Yue, X.-X.; Zhao, R.-H. Design, synthesis and antiproliferative activity studies of 1,2,3-triazole-chalcones. Medchemcomm 2016, 8, 1664-1671. 
31. Zhou, Y.; Yan, W.; Cao, D.; Shao, M.; Li, D.; Wang, F.; Yang, Z.; Chen, Y.; He, L.; Wang, T.; et al. Design, synthesis and biological evaluation of 4-anilinoquinoline derivatives as novel potent tubulin depolymerization agents. Eur. J. Med. Chem. 2017, 138, 1114-1125. [CrossRef] [PubMed]

32. Cao, D.; Liu, Y.; Xiaoyan, W.; Wang, C.; Bai, P.; Wang, T.; Tang, M.; Wang, X.; Yang, Z.; Ma, B.; et al. Design, Synthesis, and Evaluation of in Vitro and in Vivo Anticancer Activity of 4-Substituted Coumarins: A Novel Class of Potent Tubulin Polymerization Inhibitors. J. Med. Chem. 2016, 59, 5721-5739. [CrossRef] [PubMed]

33. Song, J.; Gao, Q.-L.; Wu, B.-W.; Zhu, T.; Cui, X.-X.; Jin, C.-J.; Wang, S.-Y.; Wang, S.-H.; Fu, D.-J.; Liu, H.-M.; et al. Discovery of tertiary amide derivatives incorporating benzothiazole moiety as anti-gastric cancer agents in vitro via inhibiting tubulin polymerization and activating the Hippo signaling pathway. Eur. J. Med. Chem. 2020, 203, 112618. [CrossRef] [PubMed]

34. Gao, Q.-L.; Wu, B.-W.; Li, D.; Shi, L.; Zhu, T.; Lou, J.-F.; Jin, C.-Y.; Zhang, Y.-B.; Zhang, S.; Liu, H.-M.; et al. Novel tertiary sulfonamide derivatives containing benzimidazole moiety as potent anti-gastric cancer agents: Design, synthesis and SAR studies. Eur. J. Med. Chem. 2019, 183, 111731.

35. Song, J.; Cui, X.-X.; Wu, B.-W.; Li, D.; Wang, S.-H.; Shi, L.; Zhu, T.; Zhang, Y.-B.; Zhang, S.-Y. Discovery of 1,2,4-triazine-based derivatives as novel neddylation inhibitors and anticancer activity studies against gastric cancer MGC-803 cells. Bioorganic Med. Chem. Lett. 2019, 30, 126791. [CrossRef] [PubMed]

Sample Availability: Samples of the compounds are available from the authors.

Publisher's Note: MDPI stays neutral with regard to jurisdictional claims in published maps and institutional affiliations.

(C) 2020 by the authors. Licensee MDPI, Basel, Switzerland. This article is an open access article distributed under the terms and conditions of the Creative Commons Attribution (CC BY) license (http://creativecommons.org/licenses/by/4.0/). 